\title{
ADUBAÇÃO NITROGENADA NA PRODUTIVIDADE, LEITURA SPAD E TEOR DE NITROGÊNIO EM FOLHAS DE FEIJOEIRO ${ }^{1}$
}

\author{
Edvaldo Vieira Pacheco Sant'Ana ${ }^{2}$, Alberto Baêta dos Santos ${ }^{3}$, Pedro Marques da Silveira ${ }^{3}$
}

\begin{abstract}
NITROGEN FERTILIZATION ON DRY BEAN LEAVES

YIELD, SPAD READING, AND NITROGEN LEVEL

Nitrogen deficiency is one of the most limiting yield factors for dry bean. The objective of this study was to evaluate effects of topdressing nitrogen on chlorophyll and nitrogen concentrations in dry bean (BRS Horizonte cultivar) leaves and yield. The experiment was conducted at Embrapa Arroz e Feijão, in Santo Antônio de Goiás, Goiás State, Brazil, using a dystrophic dark red latosol. The experimental design was randomized blocks with four replications. The nitrogen rates used were $0 \mathrm{~kg} \mathrm{ha}^{-1}$, $30 \mathrm{~kg} \mathrm{ha}^{-1}, 60 \mathrm{~kg} \mathrm{ha}^{-1}, 120 \mathrm{~kg} \mathrm{ha}^{-1}$, and $240 \mathrm{~kg} \mathrm{ha}^{-1}$. Half of the $\mathrm{N}$ was applied at 10 days after emergence and half was applied at 17 days after emergence, using urea as fertilizer. Grain yield and chlorophyll concentration showed quadratic response to increasing $\mathrm{N}$ rates, whereas $\mathrm{N}$ concentration in leaves increased linearly. The chlorophyll concentration increased according to plant age, while the $\mathrm{N}$ concentration in leaves decreased. Chlorophyll and $\mathrm{N}$ concentrations in leaves were positively associated with grain yield. Chlorophyll meter readings estimated adequately chlorophyll concentrations in dry bean leaves and can be used to diagnose this nutrient in dry bean.
\end{abstract}

KEY-WORDS: Phaseolus vulgaris; chlorophyll meter; nitrogen level; no-till system.

\section{INTRODUÇÃO}

O feijão (Phaseolus vulgaris L.) é uma das leguminosas mais importantes para o consumo humano, principalmente em países em desenvolvimento. No Brasil, representa alimento de alto significado social, devido ao hábito alimentar da população (Silva \& Del Peloso 2006). É a principal cultura que integra os sistemas agrícolas irrigados, nas regiões Centro-Oeste e Sudeste, com produtividades de grãos da ordem de $2.500 \mathrm{~kg} \mathrm{ha}^{-1}$ (Silveira et al. 2003). Entre as técnicas de manejo necessárias para atingir altas produtividades, nestes sistemas de cultivo, está a

\section{RESUMO}

A carência de nitrogênio é um dos fatores mais limitantes à produtividade de grãos de feijão. O objetivo deste estudo foi avaliar os efeitos de doses de nitrogênio aplicadas em cobertura sobre o teor relativo de clorofila (TRC - leitura SPAD), teor de nitrogênio nas folhas (TNF) e produtividade de grãos da cultivar BRS horizonte de feijoeiro. O experimento foi conduzido na Embrapa Arroz e Feijão, em Santo Antônio de Goiás (GO), em Latossolo Vermelho distrófico. Foi utilizado delineamento experimental de blocos ao acaso, com quatro repetições e cinco doses de nitrogênio $\left(0 \mathrm{~kg} \mathrm{ha}^{-1}, 30 \mathrm{~kg} \mathrm{ha}^{-1}\right.$, $60 \mathrm{~kg} \mathrm{ha}^{-1}, 120 \mathrm{~kg} \mathrm{ha}^{-1}$ e $240 \mathrm{~kg} \mathrm{ha}^{-1}$ ), aplicadas metade aos dez dias após a emergência (DAE) e a outra metade aos $17 \mathrm{DAE}$, na forma de ureia. A produtividade de grãos e o TRC apresentaram respostas quadráticas às doses de $\mathrm{N}$ e o TNF aumentou linearmente. O TRC aumentou com a idade das plantas, enquanto o TNF diminuiu, e ambos os teores foram associados à produtividade de grãos. As leituras efetuadas com clorofilômetro estimaram adequadamente o TRC e podem substituir a determinação do TNF, para diagnóstico do nível deste nutriente no feijoeiro.

PALAVRAS-CHAVE: Phaseolus vulgaris; clorofilômetro; teor de nitrogênio; plantio direto.

adubação nitrogenada. $\mathrm{O}$ alto custo de fertilizantes nitrogenados desperta interesse no desenvolvimento de técnicas de manejo que possam maximizar o uso eficiente do nitrogênio $(\mathrm{N})$ pelas culturas (Amado et al. 2000).

Por ser o nitrogênio o elemento mais absorvido pela planta, sua carência é altamente limitante à produtividade de grãos de feijão. A fixação simbiótica de $\mathrm{N}$ apresentada pelo feijoeiro, na maioria das vezes, não tem sido efetiva para proporcionar elevadas produtividades. A maximização do uso de $\mathrm{N}$ pelo feijoeiro, por meio de técnicas eficientes de manejo, é importante, devido a aspectos econômicos

1. Trabalho recebido em maio/2009 e aceito para publicação em dez./2010 (n ${ }^{\circ}$ registro: PAT 6320/ DOI: 10.5216/pat.v40i4.6320).

2. Engenheiro Agrônomo, Goiânia, GO, Brasil.E-mail: edvaldovps@bol.com.br.

3. Embrapa Arroz e Feijão, Santo Antônio de Goiás, GO, Brasil.E-mails: baeta@cnpaf.embrapa.br, pmarques@cnpaf.embrapa.br. 
e ambientais, pois este nutriente apresenta risco ao meio ambiente, por ser potencialmente contaminante de lençóis freáticos. Por ser um elemento que se perde facilmente por lixiviação, volatilização e desnitrificação, no sistema solo-planta, o manejo adequado da adubação nitrogenada é tido como um dos mais difíceis. Assim, torna-se necessário determinar a curva de resposta da cultura, em relação às doses do nutriente, e adotar o método mais adequado de aplicação, pois afeta o comportamento do N no solo e sua eficiência para a cultura (Fageria et al. 1999).

O clorofilômetro, que proporciona leituras instantâneas, de maneira não destrutiva de folhas, surge como alternativa de indicação do teor de clorofila presente na folha da planta (Dwyer et al. 1991, Argenta et al. 2001, Argenta et al. 2002). O conteúdo de clorofila correlaciona-se com a concentração de $\mathrm{N}$ na planta e, também, com a produtividade das culturas (Lima et al. 2001, Silveira et al. 2003). Segundo Peng et al. (1993) e Chapman \& Barreto (1997), o clorofilômetro é um aparelho que possibilita estimar, de forma rápida e barata, a concentração de $\mathrm{N}$ nas folhas das plantas e, com isto, pode contribuir para a diminuição da sub ou superutilização de fertilizantes nitrogenados. Em vários estudos, o teor relativo de clorofila determinado por meio do clorofilômetro foi usado para predizer a necessidade de adubação nitrogenada na cultura do feijoeiro (Furlani Júnior et al. 1996, Lima et al. 2001, Stone et al. 2002, Silveira et al. 2003).

O objetivo deste estudo foi avaliar os efeitos de doses de nitrogênio, aplicadas em cobertura, sobre o teor relativo de clorofila (leitura SPAD), teor de N nas folhas e produtividade de grãos, para a cultivar BRS horizonte de feijoeiro.

\section{MATERIAL E MÉTODOS}

$\mathrm{O}$ experimento foi conduzido na área experimental da Embrapa Arroz e Feijão, na Fazenda Capivara, em Santo Antônio de Goiás, GO (16 $28^{\prime} 00^{\prime \prime} \mathrm{S}, 4^{\circ} 17^{\prime} 00^{\prime}$ 'W e altitude de $\left.823 \mathrm{~m}\right)$, em Latossolo Vermelho distrófico, textura argilosa, cuja análise química da amostra superficial (0-20 cm de profundidade) apresentou teores de $34,3 \mathrm{mmol}_{\mathrm{c}} \mathrm{dm}^{-3}$ de Ca; $14,1 \mathrm{mmol}_{\mathrm{c}} \mathrm{dm}^{-3} \mathrm{de} \mathrm{Mg}$; $16,5 \mathrm{mg} \mathrm{dm}^{-3}$ de P; $92 \mathrm{mg} \mathrm{dm}^{-3} \mathrm{de} \mathrm{K}$; e $22 \mathrm{~g} \mathrm{~kg}^{-1}$ de matéria orgânica.

A semeadura foi realizada em maio de 2005, sob sistema plantio direto na palha, e o cultivo anterior foi milho em consórcio com braquiária (Brachiaria decumbens). Foi utilizada a cultivar BRS Horizonte de feijoeiro do grupo carioca, de porte ereto, com 40-60 cm de altura, hábito de crescimento indeterminado tipo II, flor branca, sementes opacas de cor bege com rajas marrons claras, com quatro a sete sementes por vagem e ciclo de 90 dias. Previamente à instalação do experimento, a área foi roçada e dessecada com glifosate, na dose de 3,0 $\mathrm{L} \mathrm{ha}^{-1}$. Na semeadura do feijão, foram colocadas 16 sementes por metro, em fileiras espaçadas em $45 \mathrm{~cm}$, o que resultou em população final de 30 plantas $\mathrm{m}^{-2}$, e a adubação empregada foi de $400 \mathrm{~kg} \mathrm{ha}^{-1}$ da fórmula comercial 4-30-16.

A área experimental foi irrigada por aspersão (sistema pivô central), sendo as irrigações efetuadas sempre que a tensão de água do solo, à profundidade de $0-15 \mathrm{~cm}$, alcançava a faixa de $25-40 \mathrm{kPa}$.

Foi utilizado o delineamento experimental em blocos ao acaso, com quatro repetições, e avaliaram-se cinco doses de $\mathrm{N}\left(0 \mathrm{~kg} \mathrm{ha}^{-1}, 30 \mathrm{~kg} \mathrm{ha}^{-1}, 60 \mathrm{~kg} \mathrm{ha}^{-1}\right.$, $120 \mathrm{~kg} \mathrm{ha}^{-1}$ e $240 \mathrm{~kg} \mathrm{ha}^{-1}$ ), aplicadas metade aos dez dias após a emergência (DAE) e a outra metade aos $17 \mathrm{DAE}$, na forma de ureia. Cada parcela teve área total e útil de $18,0 \mathrm{~m}^{2}$ e $10,8 \mathrm{~m}^{2}$, respectivamente. O teor relativo de clorofila (TRC - leitura SPAD) foi determinado mediante oito leituras com clorofilômetro, modelo Minolta SPAD-502, entre 17 DAE e $45 \mathrm{DAE}$, em 30 folhas por parcela. $\mathrm{O}$ teor de $\mathrm{N}$ nas folhas (TNF) foi determinado pelo método Kjeldahl, sendo $200 \mathrm{mg}$ de amostra digerida com $3 \mathrm{~mL}$ de ácido sulfúrico $\left(\mathrm{H}_{2} \mathrm{SO}_{4}\right)$, em presença de $1,2 \mathrm{~g}$ de uma mistura de selênio ( $\mathrm{Se})$ em pó, sulfato de cobre $\left(\mathrm{CuSO}_{4}\right.$ $\left.\mathrm{H}_{2} \mathrm{O}\right)$ e sulfato de potássio $\left(\mathrm{K}_{2} \mathrm{SO}_{4}\right)$, de acordo com Embrapa (1997).

Por ocasião da colheita, foram determinados os componentes da produtividade, números de vagens por planta e grãos por vagem, massa de 100 grãos e produtividade de grãos, a qual foi expressa em $\mathrm{kg} \mathrm{ha}^{-1}$, após a umidade ser ajustada para $13 \%$.

Os dados do TNF, TRC na folha, produtividade de grãos e de seus componentes foram submetidos a análise de variância e, quando significativos, a análise de regressão.

\section{RESULTADOS E DISCUSSÃO}

Os valores médios de TRC correlacionaram-se, linear e positivamente, com a idade das plantas, apresentando maiores valores nas maiores doses de 
$\mathrm{N}$ aplicadas em cobertura. Por outro lado, os TNF correlacionaram-se, linear e negativamente, com a idade das plantas, também apresentando maiores valores nas maiores doses de N (Figura 1). Em condições irrigadas, Silveira et al. (2003) também verificaram aumento do TRC nas folhas do feijoeiro, de acordo com as doses de $\mathrm{N}$, e os valores da leitura do clorofilômetro foram crescentes, até o início do florescimento.

Por ocasião da floração do feijoeiro, os efeitos das doses de $\mathrm{N}$ sobre o TNF foram lineares e, sobre o TRC, quadrático (Figura 2). Isto indica que o TNF relaciona-se com as doses de $\mathrm{N}$ aplicadas em cobertura no feijoeiro, enquanto o TRC atinge valor máximo com determinada dose de $\mathrm{N}$, ou seja, não aumenta indefinidamente. Blackmer \& Schepers (1995) mencionam que a vantagem da medição do teor relativo de clorofila é a de a mesma não ser influenciada pelo consumo de luxo pela planta, sob a forma de nitrato. A baixa sensibilidade do medidor
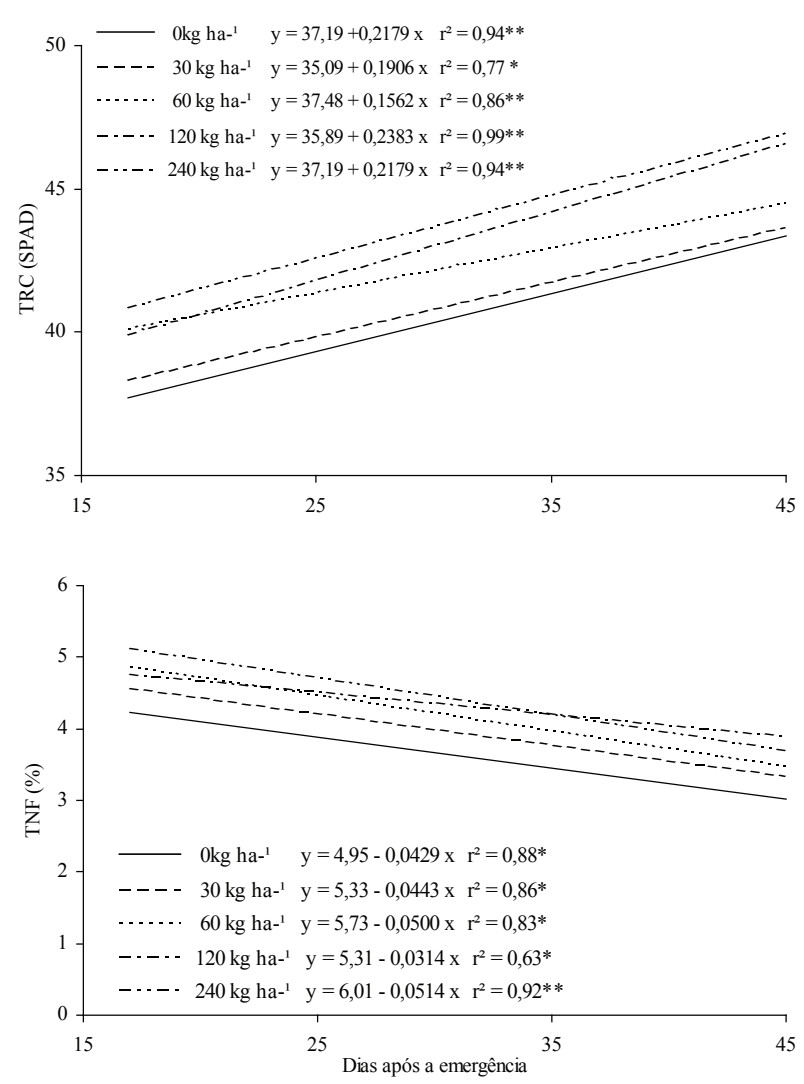

Figura 1. Evolução do teor relativo de clorofila (TRC) e do teor de nitrogênio nas folhas (TNF) do feijoeiro, em relação às doses de nitrogênio $(* * *$ : significativo a $5 \%$ e $1 \%$, pelo teste t, respectivamente) (Santo Antônio de Goiás, GO, 2005).

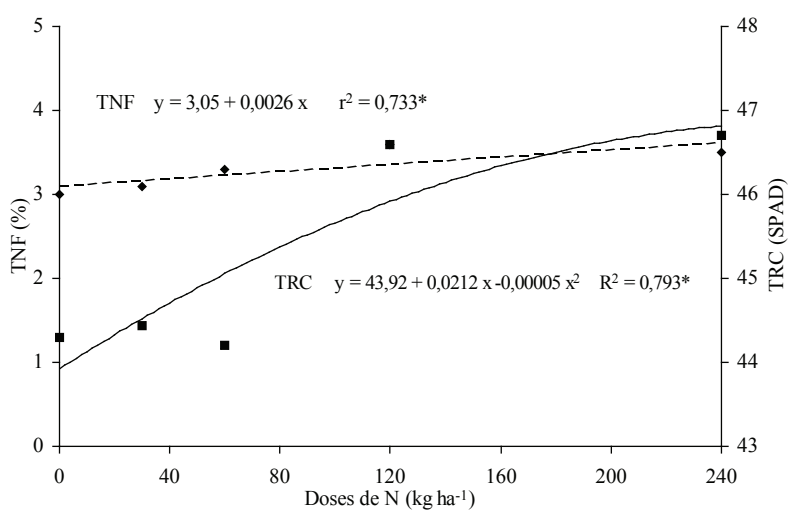

Figura 2. Teor relativo de clorofila (TRC) e teor de nitrogênio nas folhas (TNF), no florescimento do feijoeiro, em resposta às doses de nitrogênio em cobertura (* significativo a $5 \%$ de probabilidade, pelo teste $\mathrm{t}$ ) (Santo Antônio de Goiás, GO, 2005).

de clorofila ao consumo de luxo de $\mathrm{N}$ pelas plantas é atribuída à forma com que este nutriente se acumula na folha, já que, quando absorvido em excesso, acumula-se como nitrato. Nesta forma, o $\mathrm{N}$ não se associa à molécula de clorofila e, portanto, não pode ser quantificado pelo medidor de clorofila (Dwyer et al. 1995). Furlani Júnior et al. (1996) obtiveram relação significativa do TRC e do TNF, no florescimento do feijoeiro, com a adubação nitrogenada. Segundo Oliveira et al. (1996), são consideradas níveis críticos para o desenvolvimento do feijoeiro concentrações que variam de $2,8 \%$ a $6 \%$ de nitrogênio na folha. Quando resultados de análises foliares revelam concentrações de nutrientes abaixo dos níveis críticos, a cultura necessita de alguma adubação adicional, para completar seu ciclo vegetativo, em condições nutricionais adequadas.

A relação entre o TRC e o TNF, no florescimento do feijoeiro, foi linear e positiva (Figura 3). Este comportamento indica que, à medida que aumenta o teor de $\mathrm{N}$ nas folhas, o teor de clorofila aumenta proporcionalmente. Este resultado está de acordo com os obtidos por Furlani Júnior et al. (1996), Caires \& Rosolem (1999) e Carvalho et al. (2003). A relação verificada entre o TRC e o TNF (Figura 3) evidencia que as leituras efetuadas com clorofilômetro estimam adequadamente o grau de esverdeamento da folha de feijoeiro, ou seja, o TRC na folha, podendo substituir a determinação do TNF, para diagnóstico do nível deste nutriente na planta. Argenta et al. (2001) verificaram que o TRC na folha é um bom parâmetro indicador do nível de $\mathrm{N}$ em 


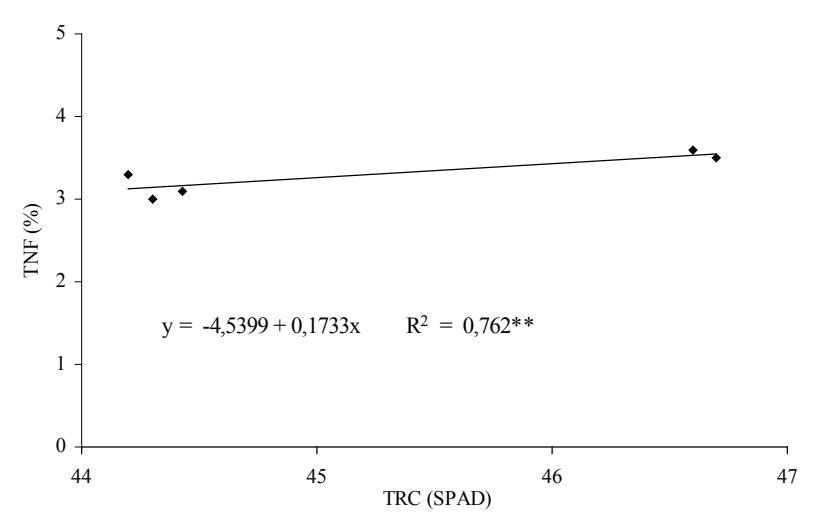

Figura 3. Relação entre teor de nitrogênio nas folhas (TNF) e teor relativo de clorofila (TRC), por ocasião do florescimento do feijoeiro. $(* *$ significativo a $1 \%$, pelo teste de t) (Santo Antônio de Goiás, GO, 2005).

cereais. Em estudo de Silveira et al. (2003), o clorofilômetro foi eficaz, como instrumento indicador da necessidade de adubação nitrogenada em cobertura no feijoeiro. Barbosa Filho et al. (2005) verificaram maior eficiência do fertilizante nitrogenado, quando se utilizou o clorofilômetro como indicador da necessidade de aplicação de $\mathrm{N}$ em cobertura, do que a aplicação baseada em épocas pré-fixadas para a adubação.

A utilização do clorofilômetro, para se estimar os teores de clorofila nas folhas, apresenta algumas vantagens, com relação ao método químico de análise de $\mathrm{N}$ na folha: a leitura pode ser realizada em poucos minutos; o aparelho tem custo mínimo de manutenção, ao contrário de outros métodos que exigem compra sistemática de produtos químicos (Piekielek \& Fox 1992); não há necessidade de envio de amostras para laboratório, com economia de tempo e dinheiro; e podem ser realizadas quantas amostragens forem necessárias, sem implicar em destruição de folhas (Dwyer et al. 1991). De maneira contrária, além de ser influenciado pelo consumo de luxo de $\mathrm{N}$ e de envolver análise laboratorial, a determinação do TNF apresenta a grande desvantagem de não possibilitar a correção de sua deficiência na planta, no mesmo ano agrícola, devido ao tempo despendido entre a coleta e o resultado final, o que permite que os resultados sejam informativos, servindo apenas como parâmetro indicativo para os próximos cultivos.

As relações entre o TRC e o TNF, por ocasião do florescimento do feijoeiro, com a produtividade de grãos foram lineares e positivas (Figura 4). Cada unidade SPAD correspondeu a um incremento de $436 \mathrm{~kg} \mathrm{ha}^{-1}$ de grãos, enquanto o aumento de $1 \%$ do TNF equivaleu à adição de $1.807 \mathrm{~kg} \mathrm{ha}^{-1}$ de grãos de feijão. Os altos coeficientes de determinação destas relações $(0,825$ e 0,814 , respectivamente) evidenciam que tanto o TRC como o TNF estão altamente associados à produtividade de grãos. Nas culturas de milho (Piekielek et al. 1995) e do feijoeiro (Silveira et al. 2003), as leituras SPAD correlacionaram-se linearmente com a produtividade de grãos.

Aos efeitos das doses de $\mathrm{N}$ sobre a produtividade de grãos de feijão ajustou-se o modelo quadrático, sendo $140 \mathrm{~kg} \mathrm{ha}^{-1}$ de $\mathrm{N}$ a dose estimada por meio da equação de regressão, para a obtenção de $3.756 \mathrm{~kg} \mathrm{ha}^{-1}$ de grãos da cultivar BRS Horizonte. A dose necessária para a máxima eficiência técnica, ou seja, aquela que proporcionou $90 \%$ da máxima produtividade de grãos $\left(3.383 \mathrm{~kg} \mathrm{ha}^{-1}\right)$, foi de $76 \mathrm{~kg} \mathrm{ha}^{-1}$ de N (Figura 5). Com a cultivar Jalo Precoce de feijoeiro, Silveira et al. (2003) obtiveram resposta linear de até $120 \mathrm{~kg} \mathrm{ha}^{-1} \mathrm{de} \mathrm{N}$, ao passo que a
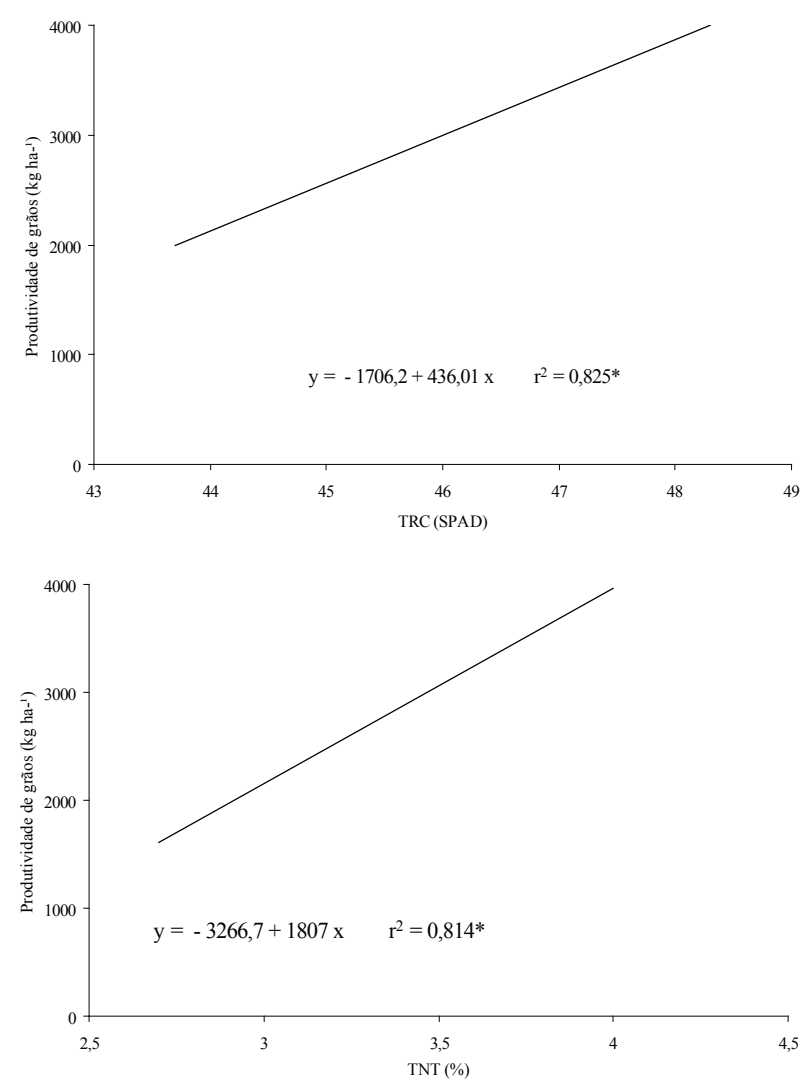

Figura 4. Relação entre o teor relativo de clorofila (TRC) e o teor de nitrogênio nas folhas (TNF) do feijoeiro, segundo a produtividade de grãos. (* significativo a 5\%, pelo teste t) (Santo Antônio de Goiás, GO, 2005). 


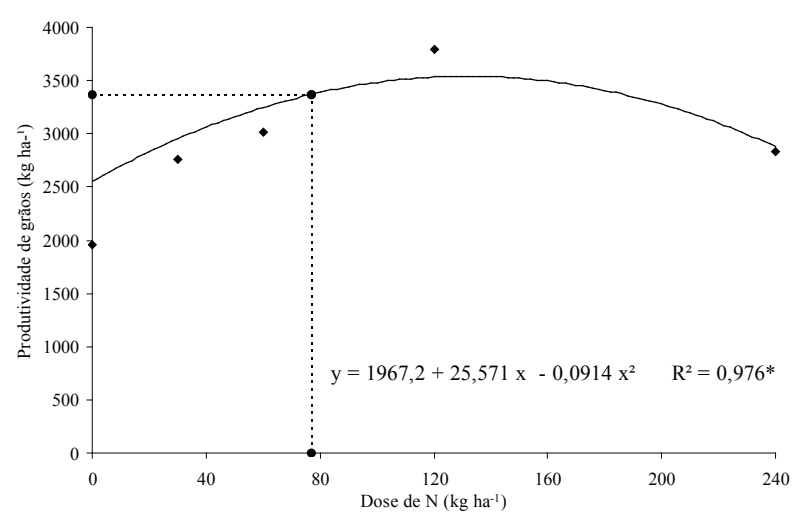

Figura 5. Produtividade de grãos da cultivar BRS Horizonte de feijoeiro, em resposta às doses de nitrogênio em cobertura (* significativo a $5 \%$, pelo teste $\mathrm{t}$ ) (Santo Antônio de Goiás, GO, 2005).

produtividade máxima da cultivar Pérola foi estimada com $62 \mathrm{~kg} \mathrm{ha}^{-1}$ de N. Em solo de várzea, Santos et al. (2003) determinaram a máxima eficiência técnica com a dose de $108 \mathrm{~kg} \mathrm{ha}^{-1}$ de N, incorporados ao solo aos 20 DAE. Carvalho et al. (2001), estudando o efeito de fontes e diferentes parcelamentos do $\mathrm{N}$ em feijoeiro de inverno, concluíram que a aplicação de $75 \mathrm{~kg} \mathrm{ha}^{-1}$ de $\mathrm{N}$ proporcionou, em média, incremento de $38 \%$ na produtividade da cultura.

A elevada exigência de $\mathrm{N}$ pelo feijoeiro, neste estudo, possivelmente se deve aos resíduos deixados na superfície do solo, pela cultura antecessora, milho em consórcio com braquiária (Brachiaria decumbens), que propiciaram maior imobilização e menor disponibilidade do nutriente para a cultura, pois parte do $\mathrm{N}$ foi, presumivelmente, consumida pela população microbiana do solo, durante o processo de decomposição da palhada. A magnitude em que a imobilização do $\mathrm{N}$ mineral afeta a sua disponibilidade para a cultura subsequente depende da relação $\mathrm{C} / \mathrm{N}$, composição e quantidade de resíduos produzidos pela cultura anterior (Fageria et al. 1999).

\section{CONCLUSÕES}

1. A produtividade de grãos e a leitura SPAD apresentaram respostas quadráticas às doses de nitrogênio e o teor de nitrogênio nas folhas do feijoeiro aumentou linearmente.

2. A leitura SPAD aumentou de acordo com a idade das plantas de feijoeiro, enquanto o teor de nitrogênio diminuiu.
3. A leitura SPAD e o teor de nitrogênio nas folhas do feijoeiro correlacionaram-se, positivamente, com a produtividade de grãos.

4. As leituras efetuadas com clorofilômetro estimaram adequadamente o teor relativo de clorofila e podem substituir a determinação do teor de nitrogênio nas folhas, para diagnóstico do nível deste nutriente no feijoeiro.

\section{REFERÊNCIAS}

AMADO, T. J. C.; MIELNIZUK, J.; FERNÁNDEZ, S. B. V. Leguminosas e adubação mineral como fontes de nitrogênio para o milho em sistemas de preparo do solo. Revista Brasileira de Ciência do Solo, Viçosa, v. 24, n. 1, p. 179-189, 2000.

ARGENTA, G.; SILVA, P. R. F. da; BORTOLINI, C. G. Clorofila na folha como indicador de nitrogênio em cereais. Ciência Rural, Santa Maria, v. 31, n. 4, p. 715-722, 2001.

ARGENTA, G.; SILVA, P. R. F. da; BORTOLINI, C. G. Parâmetros de planta como indicadores do nível de nitrogênio na cultura do milho. Pesquisa Agropecuária Brasileira, Brasília, DF, v. 37, n. 4, p. 519-527, 2002.

BARBOSA FILHO, M. P.; COBUCCI, T.; MENDES, P. N. Adubação nitrogenada no cultivo do feijoeiro comum irrigado sob plantio direto. Santo Antônio de Goiás: Embrapa Arroz e Feijão, 2005. (Circular técnica, 70).

BLACKMER, T. M.; SCHEPERS, J. S. Techniques for monitoring crop nitrogen status in corn. Communications in Soil Science and Plant Analysis, New York, v. 25, n. 9/10, p. 1791-1800, 1995.

CAIRES, E. F.; ROSOLEM, C. A. Efeitos da calagem, cobalto e molibdênio sobre a concentração de clorofila nas folhas de amendoim. Revista Brasileira de Ciência do Solo, Viçosa, v. 23, n. 1, p. 79-84, 1999.

CARVALHO, M. A. C. et al. Doses e épocas de aplicação de nitrogênio e teores foliares deste nutriente e de clorofila em feijoeiro. Revista Brasileira de Ciência do Solo, Viçosa, v. 27, n. 3, p. 445-450, 2003.

CARVALHO, M. A. C. et al. Produtividade e qualidade de sementes de feijoeiro (Phaseolus vulgaris L.) sob influência de parcelamento e fontes de nitrogênio. Revista Brasileira de Ciência do Solo, Viçosa, v. 25, n. 3, p. 617624, 2001.

CHAPMAN, S. C.; BARRETO, H. J. Using a chlorophyll meter to estimate specific leaf nitrogen of tropical maize during vegetative growth. Agronomy Journal, Madison, v. 89 , n. 4 , p. 557-562, 1997. 
DWYER, L. M.; TOLLENAAR, M.; HOUWING, L. A nondestructive method to monitor leaf greenness in corn. Canadian Journal of Plant Science, Ottawa, v. 71, n. 3, p. 505-509, 1991.

DWYER, L. M.; ANDERSON, A. M.; MA, B. L. Quantifying the nonlinearity in chlorophyll meter response to corn leaf nitrogen concentration. Canadian Journal of Plant Science, Ottawa, v. 75, n. 1, p. 179-182, 1995.

EMPRESA BRASILEIRA DE PESQUISA AGROPECUÁRIA (Embrapa). Manual de métodos de análise de solo. 2. ed. rev. atual. Rio de Janeiro: Embrapa, 1997. (Documentos, 1).

FAGERIA, N. K.; STONE, L. F.; SANTOS, A. B. dos. Maximização da eficiência de produção das culturas. Brasília, DF: Embrapa-SCT/Embrapa-CNPAF, 1999.

FURLANI JÚNIOR, E. et al. Correlação entre leituras de clorofila e níveis de nitrogênio aplicados em feijoeiro. Bragantia, Campinas, v. 55, n. 1, p. 171-175, 1996.

LIMA, E. do V. et al. Adubação NK no desenvolvimento e na concentração de macronutrientes no florescimento do feijoeiro. Scientia Agricola, Piracicaba, v. 58, n. 1, p. 125-129, 2001.

OLIVEIRA, I. P. de; ARAÚJO, R. S.; DUTRA, L. G. Nutrição mineral e fixação biológica de nitrogênio. In: ARAÚJO, R. S. et al. (Coords.). Cultura do feijoeiro comum no Brasil. Piracicaba: Potafos, 1996. p. 169-221.

PENG, S. et al. Adjustment for specific leaf weight improves chlorophyll meter's estimate of rice leaf nitrogen concentration. Agronomy Journal, Madison, v. 85, n. 5, p. 987-990, 1993.
PIEKIELEK, W. P.; FOX, R. H. Use of a chlorophyll meter to predict side dress nitrogen requirements for maize. Agronomy Journal, Madison, v. 84, n. 1, p. 59-65, 1992.

PIEKIELEK, W. P. et al. Use of a chlorophyll meter at the early dent stage of corn to evaluate nitrogen sufficiency. Agronomy Journal, Madison, v. 87, n. 3, p. 403-408, 1995.

SANTOS, A. B. dos et al. Resposta do feijoeiro ao manejo de nitrogênio em várzeas tropicais. Pesquisa Agropecuária Brasileira, Brasília, DF, v. 38, n. 11, p. 1265-1271, 2003.

SILVA, C. C. da; DEL PELOSO, M. J. (Eds.). Informações técnicas para o cultivo do feijoeiro comum na região central-brasileira 2005-2007. Santo Antônio de Goiás: Embrapa Arroz e Feijão, 2006. (Documentos, 193).

SILVEIRA, P. M. da; BRAZ, A. J. B. P.; DIDONET, A. D. Uso do clorofilômetro como indicador da necessidade de adubação nitrogenada em cobertura no feijoeiro. Pesquisa Agropecuária Brasileira, Brasília, DF, v. 38, n. 9, p. 1083$1087,2003$.

STONE, L. F.; SILVA, G. M.; MOREIRA, J. A. A. Uso do clorofilômetro SPAD-502 na estimativa do nitrogênio foliar específico e da produtividade do feijoeiro. In: CONGRESSO NACIONAL DE PESQUISA DE FEIJÃO, 7., 2002, Viçosa. Resumos Expandidos... Viçosa: UFV, 2002. p 743-746. 